\title{
Электронная форма учебника как средство обучения русскому языку
}

Павельева Т.И., учитель русского языка и литературы МОУ СОШ №2, 2. Нерюнгри, E-mail: pavelevatanjusha@rambler.ru

Ю.А. Конаржевский дает определение современному уроку. По его мнению, современный урок - это, прежде всего урок, на котором учитель умело использует все возможности для развития личности ученика, ее активного умственного роста, глубокого и осмысленного усвоения знаний, для формирования ее нравственных основ. [4, стр. 5]

Развиваются технологии - изменяются и требования, предъявляемые к содержанию учебного процесса. В настоящее время мы, учителя, должны не столько давать знания, сколько учить детей учиться, самостоятельно находить источники пополнения знаний. Чтобы школа не проиграла в соревновании с широкой доступностью услуг Интернета, необходимо с максимально большей пользой для ребенка использовать возможности этого столь привлекательного для современных школьников ресурса. Один из таких привлекательных ресурсов - ЭФУ (электронная форма учебника).

Электронная форма учебника (далее - ЭФУ) - это электронное издание, соответствующее по структуре, содержанию и художественному оформлению печатной форме учебника и содержащее мультимедийные элементы и интерактивные ссылки, расширяющие и дополняющие содержание учебника (определение МОН РФ по Приказу от 8 декабря 2014 г. № 1559). [8]

Электронная форма учебника по сравнению с традиционной печатной формой обладает преимуществами. Следующая таблица делает сравнительный анализ полиграфических и электронных форм учебников более наглядным. [2, стр. 9-10]

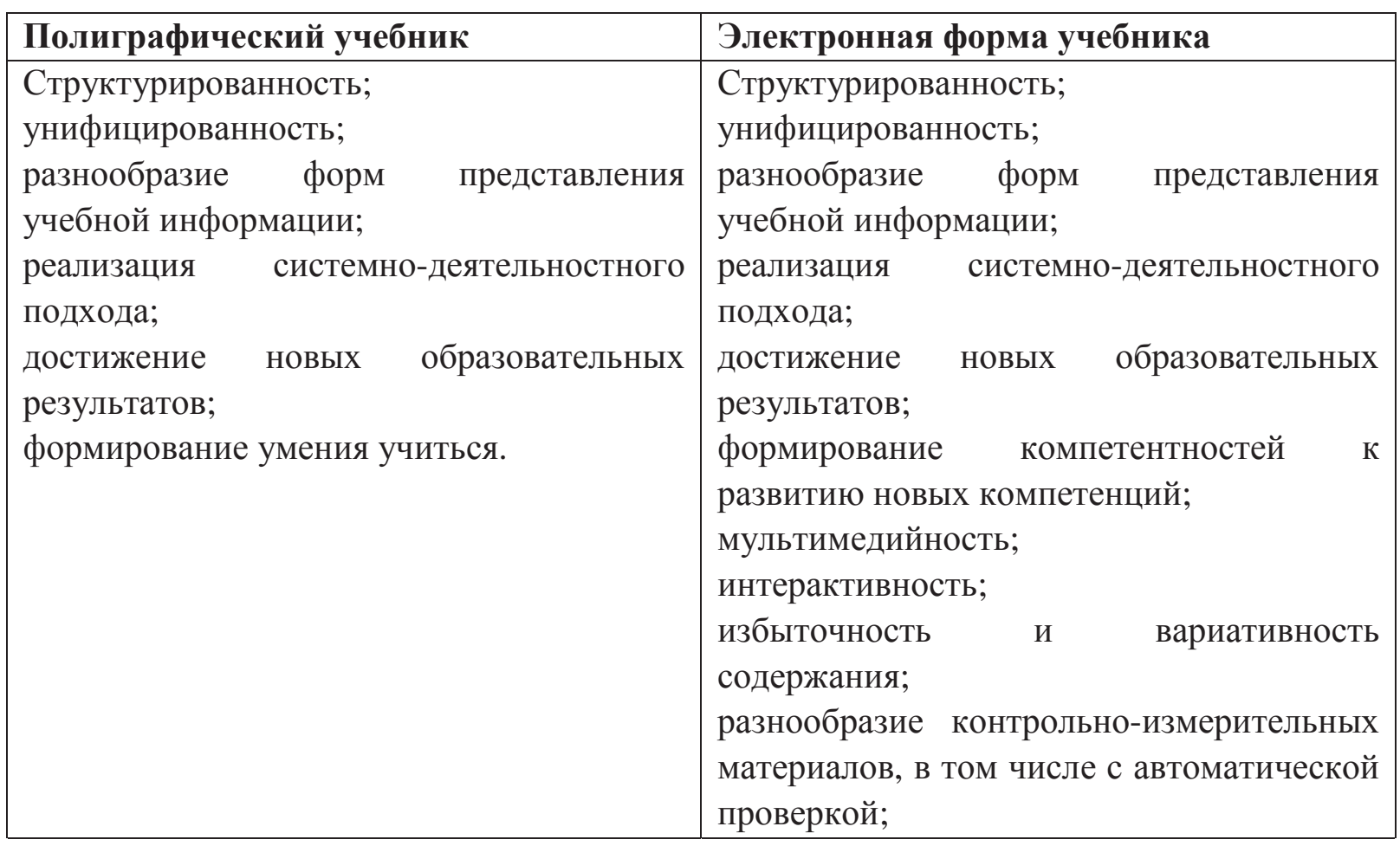




\begin{tabular}{|l|l|}
\hline & наличие дополнительных инструментов и \\
& сервисов; \\
& возможность нелинейного освоения \\
& учебного материала; \\
& учет личностных особенностей учащихся; \\
активно-деятельностные формы работы с \\
учебным содержанием.
\end{tabular}

Именно поэтому, согласно приказу МОН РФ от 8 декабря 2014 г. № 1559 г. «О внесении изменений в Порядок формирования федерального перечня учебников...», каждый учебник в печатной форме, включенный в федеральный перечень, в обязательном порядке сопровождается его представлением в электронной форме. [8]

Методика и приёмы работы с текстом в случае использования электронных форм учебников аналогичны методикам работы с полиграфическими материалами. Работа с основным текстом ЭФУ обязательно включается в начальные этапы дидактического цикла: он является, с одной стороны, основным источником новой информации, а с другой - базой для структурирования и упорядочивания имеющихся у учащихся предварительных знаний по изучаемой теме.

Представление о возможностях использования ЭФУ в учебном процессе даёт следующая таблица. [2, стр. 24-26]

\begin{tabular}{|c|c|}
\hline $\begin{array}{l}\text { Направления } \\
\text { использования ЭФУ }\end{array}$ & Примеры использования \\
\hline Источник нового знания & $\begin{array}{l}\text { Индивидуальная работа с содержанием на } \\
\text { индивидуальных устройствах: планшетах, компьютерах и } \\
\text { т.д.; групповая работа в компьютерных классах; } \\
\text { фронтальная работа с использованием проекционного } \\
\text { оборудования. }\end{array}$ \\
\hline $\begin{array}{l}\text { Источник } \\
\text { дополнительной } \\
\text { информации }\end{array}$ & $\begin{array}{l}\text { Визуализация сложных процессов и явлений для } \\
\text { расширения и углубления знаний; использование } \\
\text { мультимедийных компонентов для } \\
\text { исследовательских заданий; индивидуальная работа с } \\
\text { малыми группами по индивидуальным маршрутам. }\end{array}$ \\
\hline $\begin{array}{l}\text { База мультимедийных } \\
\text { объектов }\end{array}$ & $\begin{array}{l}\text { Использование мультимедийных } \\
\text { конструирования урока; ресурс для выполнения } \\
\text { различных учебных заданий, в том числе } \\
\text { хворактера. }\end{array}$ \\
\hline $\begin{array}{l}\text { База средств проверки и } \\
\text { контроля знаний }\end{array}$ & 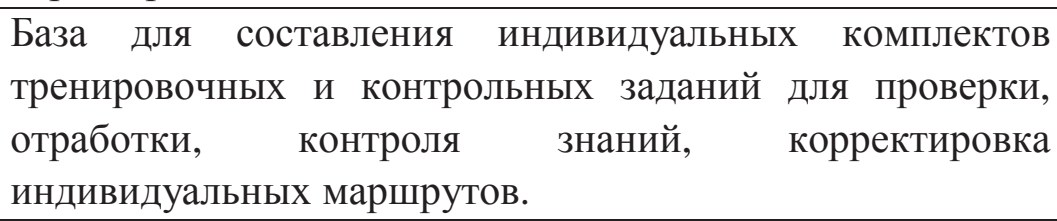 \\
\hline $\begin{array}{l}\text { Средства освоения } \\
\text { основных приемов работы } \\
\text { с информацией } \quad \text { и } \\
\text { информационного поиска. }\end{array}$ & $\begin{array}{l}\text { Освоение учащимися способов поиска, сохранения, } \\
\text { преобразования информации, учебников под } \\
\text { индивидуальные особенности с помощью инструментов } \\
\text { создания заметок и закладок. }\end{array}$ \\
\hline
\end{tabular}




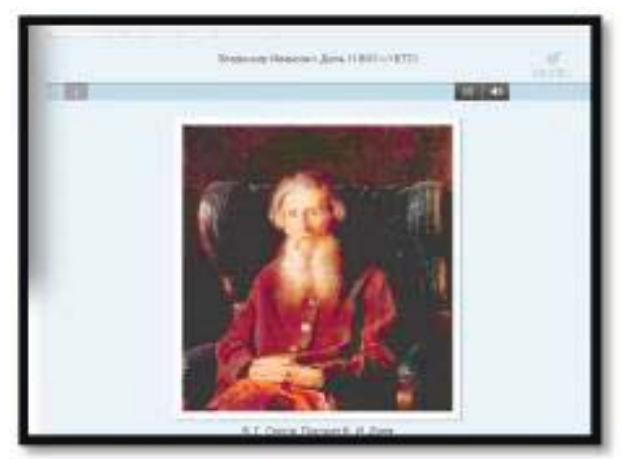

Источник нового знания: прочитайте, пожалуйста, текст на стр. 119 и ответьте на вопросы...

При этом у учащихся есть возможность не только прочитать, но и прослушать данный текст, а также они могут рассмотреть портрет ученого подробно.

Источник дополнительной информации: можно прослушать, как правильно произносится то или иное слово. Просмотреть значение слова, наведя курсор на звездочку.

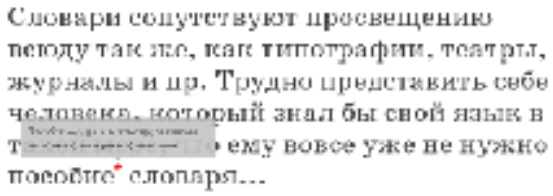

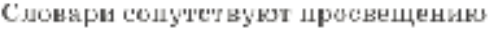
петоду таке sте, теаге титотрафит, теат рт.т, журналы и шр. Трудно црндетавить себе

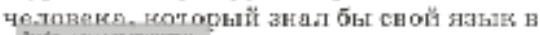
т поеобте слопирл...

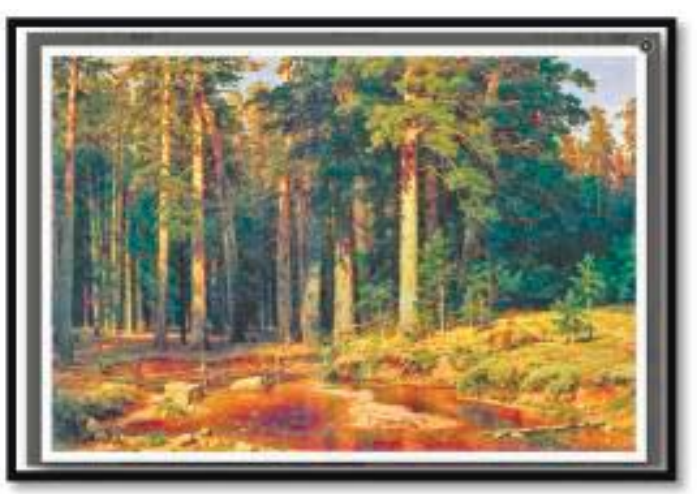

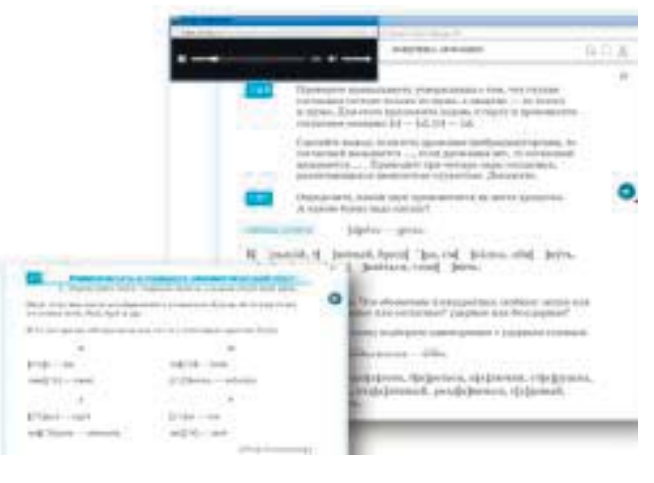

База мультимедийньх объектов: очень хорошо использовать на уроках развития речи, при подготовке к сочинению, поскольку у ученика есть возможность рассмотреть картину внимательнее за счет увеличения ее масштаба. При написании сжатого изложения прослушивание текста максимально приближает учащихся к формату этого задания на экзамене.

Аудиофайлы содержат не только информацию, но и образцы выразительного чтения, способствуя формированию правильной речи.

База средств проверки и контроля знаний: можно использовать на любом этапе урока. Например, вставить пропущенную букву при закреплении темы «Правописание чередующихся гласных а-о в корнях -лаг- - лож-, -рос- - -раст- (-ращ-)».

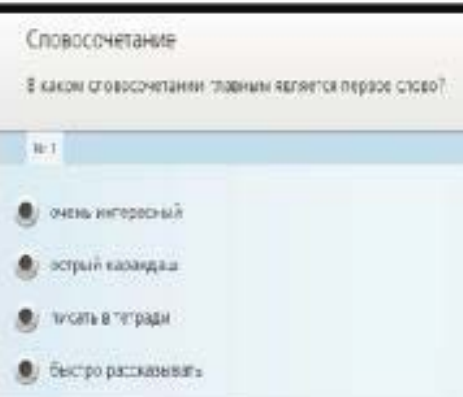

Или выбрать ответ из ниспадающего списка при изучении темы «Словосочетание»; вставить пропущенные буквы, расставляя недостающие знаки препинания.

Ученик может быстро проверить выполненное задание, скорректировать дальнейшую работу. 
Такие упражнения вызывают интерес у учащихся, так как сразу позволяют получить объективную «оценку» собственных знаний.

В процессе усвоения материала ученики могут создавать закладки, чтобы быстро находить нужную информацию, отмечать разделы, которые для них трудны.

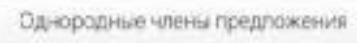

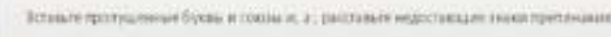

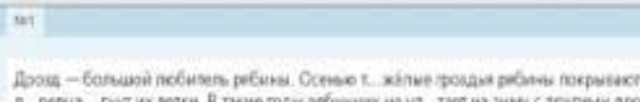

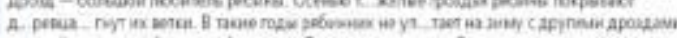

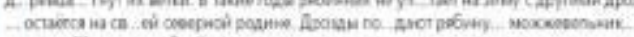

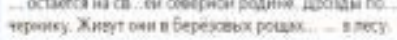

Работа с ЭФУ в классе может иметь следующие формы.

Вариант 1. Сочетание традиционных полиграфических учебников и электронных форм учебников. Вводную часть занятия, опрос, мотивирующую часть можно провести на базе полиграфических учебников, а изучение нового материала организовать в виде самостоятельной групповой работы с основными и дополнительными материалами ЭФУ. Информационная насыщенность, а иногда и избыточность мультимедийного наполнения позволит настроиться на индивидуальные особенности учащихся и их групп, сформированных исходя из учебных задач.

Вариант 2. Обращение к ЭФУ происходит на этапе закрепления материала или на этапе рефлексии.

Вариант 3. На уроках обобщения, закрепления, повторения, подготовки к контрольным работам ЭФУ целесообразно использовать фрагментарно, например, когда требуется быстро найти необходимую информацию, причём делать это можно по нескольким учебникам для различных предметов, что будет способствовать реализации метапредметных связей. [2, стр. 30-31]

Если ученический коллектив представлен детьми, которые сильно различаются по своим психологическим особенностям, уровню мотивации, сформированности ИКТкомпетентности и регулятивных универсальных учебных действий, то в этом случае класс делится на группы, в одной из которых основное обучение ведётся с ЭФУ, а личное взаимодействие с учителем используется для консультирования, группового или индивидуального. В другой группе основное обучение ведётся в традиционной форме, а обучение с использованием ЭФУ служит для поддержки и отработки навыков.

При проведении уроков с использованием ЭФУ я заметила, что ученикам очень интересно работать, они с удовольствием читают текст, рассматривают картинки, бурно обсуждают прослушанный аудиофрагмент. Также легко находят ответы на вопросы, так как они даны в простой, доступной форме. Они относятся к этому как к игре, со своими правилами, и при этом понимают, что несоблюдение этих правил не даст возможность пройти этот тур, т.е. понять заданную тему. Именно такое «легкое» отношение психологически раскрепощает ученика, позволяет раскрыть свой творческий потенциал, развивает интеллект.

При ведении такого урока меняется роль учителя, он становится другом, советчиком. Некоторые вопросы обсуждаются с учащимися «на равных», выдвигаются различные предположения, так как работа идет интерактивно и всегда можно обратиться к ЭФУ для подтверждения своей версии.

Также у учащихся закрепляются навыки работы на компьютере, они хорошо и быстро ориентируются в ЭФУ, с интересом отвечают на тестовые вопросы, это формирует способность учащихся к самообучению, самообразованию, самоорганизации и самореализации. 
Использование ЭФУ на уроках русского языка способствует формированию коммуникативной и информационной компетенций у обучающихся, активности, самостоятельности, духовности и нравственных ориентиров.

Таким образом, активное использование ЭФУ приводит к изменению в содержания образования, технологии обучения и отношениях между участниками образовательного процесса.

Список литературы:

1. Агеев В.Н. Электронная книга: новое средство социальной коммуникации - Москва, 1997. - С. 3 - 231.

2. Масленикова О.Н. Работа с электронной формой учебника истории. Москва, 2016. - С. 3 - 51.

3. Родин В.П. Создание электронного учебника: концепция и способ реализации [Текст]: учеб.издание / В.П. Родин. - М.: Венец, 2008. - 31 с.

4. Система. Урок. Анализ. Ю.А. Конаржевский. - 2-е изд. - Псков: ПОИКПРО, 2012. - 400 с.

5. Тоискин В.С., Красильников В.В. Теоретические основы разработки электронных образовательных изданий (антропологический подход) [Текст]: учеб.пособ. / В.С. Тоискин, В.В. Красильников. - Ставрополь: СГПИ, 2010. - 108 с.

6. http://efu.drofa.ru/what-is-electroni-textbook/faq.php

7. https://lecta.ru/help/efu_about\#

8. $\quad$ https://normativ.kontur.ru/document?moduleId=1\&documentId=244954

\section{Песенные тексты как отражение гражданской позиции}

Павлов Ф.С., студент, Технический институт (филиал) Северо-Восточного федерального университета, 2. Нерюнгри

E-mail: errormacro438@gmail.com

Научный руководитель: стариий преподаватель Желябина А.Г.

В настоящем исследовании рассматриваются песенные тексты популярных хипхоп исполнителей США и Великобритании, и проводится их сравнительносопоставительный анализ с целью изучения гражданской позиции авторов.

Хип-хоп в последние годы занимает нишу одного из особенно популярных жанров среди молодого поколения Соединенных Штатов и Великобритании. Этот жанр музыки является превосходным средством выражения собственной точки зрения его исполнителей. Данное направление призвано формировать у молодежи собственную гражданскую позицию, также его отличает возможность через использование различных языковых средств и приёмов говорить на острые вопросы, поднимать наболевшие темы на языке понятном и доступном различным социальным слоям населения. 